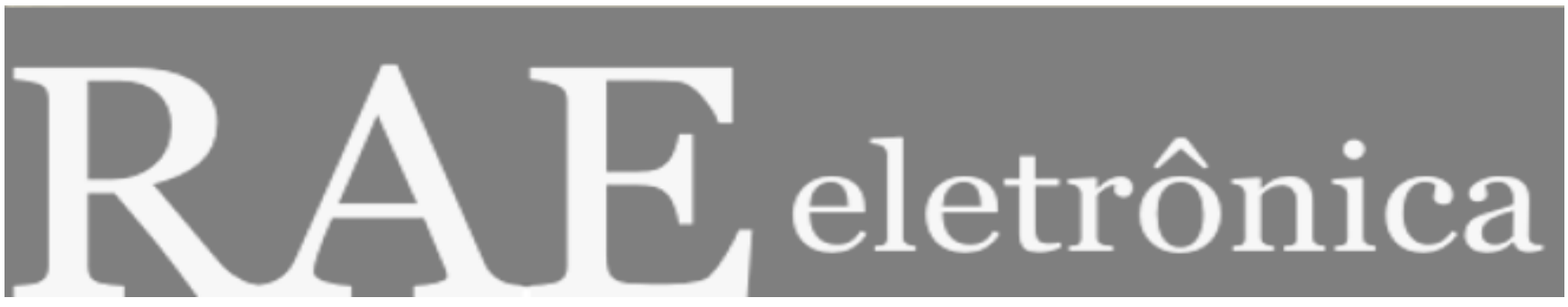

\title{
COMPORTAMENTO DO CONSUMIDOR
}

Por

Valter Afonso Vieira

RAE-eletrônica, Volume 2, Número 1, jan-jun/2003.

http://www.rae.com.br/eletronica/index.cfm?FuseAction=Artigo \&ID=1255\&Secao=RESENHAS\&Volume $=2 \&$ Numero $=1$ $\& A n o=2003$

CCopyright, 2002, RAE-eletrônica. Todos os direitos, inclusive de tradução, são reservados. É permitido citar parte de artigos sem autorização prévia desde que seja identificada a fonte. A reprodução total de artigos é proibida. Os artigos só devem ser usados para uso pessoal e não-comercial. Em caso de dúvidas, consulte a redação: redacao@rae.com.br.

A RAE-eletrônica é a revista on-line da FGV-EAESP, totalmente aberta e criada com o objetivo de agilizar a veiculação de trabalhos inéditos. Lançada em janeiro de 2002, com perfil acadêmico, é dedicada a professores, pesquisadores e estudantes. Para mais informações consulte o site www.rae.com.br/eletronica.

RAE-eletrônica

ISSN 1676-5648

(C)2002 Editora: Fundação Getulio Vargas - Escola de Administração de Empresas de São Paulo.
F U N D A Ç Ã 0 GETULIO VARGAS

Escola de Administração de Empresas de São Paulo 


\section{COMPORTAMENTO DO CONSUMIDOR}

\section{Por Valter Afonso Vieira}

Bacharel em Administração de Empresas e Marketing pela UNOPAR, Tutor em Educação a Distância pelo NEAD/UFPR e Professor Assistente de Marketing na Universidade Paranaense (UNIPAR).

E-mail: valter23@yahoo.com

Comportamento do Consumidor

Karsaklian, Eliane

São Paulo: Atlas, 2000. 303p.

No final da década de 1960, diversos profissionais ${ }^{\mathrm{i}}$ concentraram seus esforços para moldar aquela que seria uma das muitas áreas empresariais, e uma das disciplinas acadêmicas mais investigadas de todo o mundo, o "comportamento do consumidor" (consumer behavior). Logo após a publicação daquilo que Holbrook (1987) buscou delinear como pesquisa do consumidor, este campo solidificou-se e cresceu ainda mais, recebendo adeptos de diversas áreas, tais como, macro e microeconomia, psicologia, antropologia, sociologia, dentre outras. Entretanto, no Brasil, podemos dizer que sua conjuntura encontra-se em fase de amadurecimento. O professor Vieira (1999), diante do resultado de uma pesquisa realizada com os principais acadêmicos brasileiros, em uma recente exibição na Associação Nacional de Pós-Graduação em Administração de Empresas (ANPAD), apresentou o comportamento do consumidor como sendo o principal tópico para novos estudos e pesquisas.

Com base nessa prioridade apontada, o livro da brasileira Eliane Karsaklian, Comportamento do Consumidor publicado pela Atlas pondera assuntos que envolvem esse campo como clientes, consumo, marketing e comportamento. A professora Eliane obteve seu PhD em Marketing pela École des Hautes Études Commerciales HEC - França, e atua como professora na UFRGS.

Em uma obra bem estruturada, com seis breves capítulos a autora facilita a conexão de idéias para o leitor. Eliane revela-se arrojada ao publicar um dos poucos livros brasileiros desta temática ${ }^{\text {ii }}$. Após um mistura de introdução e resumo, a autora inicia com o Consumidor no Divã, no qual é estudado, analisado e pesquisado o porquê de consumirmos. Em seguida é apresentada uma revisão nas teorias motivacionais que orientam o comportamento humano, incorporando as quatro principais doutrinas: a behaviorista, cognitivista, psicanalítica e humanista. Uma crítica positiva deve ser ressalvada com relação a revisão sintética dessas teorias, já que a autora consegue transmitir ao leitor uma compreensão inicial do surgimento e do funcionamento dessas teorias no ser humano.

No segundo capítulo, Consumidor na Sociedade, Eliane esclarece ao leitor como a sociedade e seu meio ambiente influenciam no comportamento de compra do indivíduo. A culpa maior dessa influência, positiva ou negativa para aquisição ou rejeição de produtos, pode estar em: grupos de referência; líderes de opinião; classes sociais; estilos de vida (pragmáticos, responsáveis, integrados, jovens, etc.) e união da cultura e subcultura. Na abordagem desses cinco fatores considerados fundamentais para as estratégias da organização a revisão é superficial ficando sem profundidade algumas das variáveis. Uma abordagem mais precisa em cada fator ou, até mesmo, a criação de um capítulo próprio, como apresentado na obra dos pesquisadores Engel, Blackwell \& Miniard (2000), poderia ser uma boa sugestão. 
No terceiro capítulo a abordagem se dá em torno do processo de Compra do Consumidor. Neste rico e importante ponto Eliane apresenta e comenta os mais proeminentes modelos de tomada de decisão referenciados na literatura do comportamento do consumidor, a saber, Engel, Kollat \& Blackwell; Nicosia; e Howard \& Sheth. Raros são os trabalhos nacionais como o de Goldstein \& Almeida (2000) que analisam vários modelos existentes de tomada de decisão em conjunto.

Excelentes gráficos são utilizados para explanar como o consumidor realiza o processo de tomada de decisão e quais são as principais variáveis e fatores que estão envolvidos no nesmo. A decisão do consumidor de comprar ou não um produto ou serviço é um fator importante tanto para as empresas, quanto para os profissionais de marketing, pois essa decisão analisa se uma estratégia foi inteligente, perceptiva e eficaz. Assim, a explicitação dos três modelos disponibiliza subsídios para o estrategista conhecer mais profundamente como funciona esse processo.

O Consumidor na Infância é o mote analisado na seqüência. Este capítulo recebe uma profundidade maior, em decorrência da tese de doutoramento da autora e de alguns papers publicados na área (e.g. Journal of Consumer Research e Revue Française du Marketing). A influência da propaganda sobre o comportamento das crianças é analisada de modo particular, além da complementação da revisão dessas influências no ato de consumo dos pais. De acordo com Eliane "...as crianças consomem grande número de doces, mas pareceria que sua influência transcende a barreira dos produtos que lhe são destinados, pois quando os pais não têm preferências por uma marca, a opinião das crianças pode ser determinante" para a escolha (p.218). Muito bem descrito e explanado, apresenta-se como um dos poucos livros que abordaram o assunto do consumo na infância (e.g. a socialização da criança e a criança e a propaganda) com grande envergadura.

A quinta parte, o Consumidor Internacional, consagra à internacionalização dos produtos, das propagandas e do comportamento do consumidor. Na hodierna globalização, a empresa que não modificar sua estratégia para os diferentes segmentos e nichos de mercado, obterá sérias conseqüências desagradáveis explica a autora. A organização deve buscar atuação internacional, mas sempre pensando e agindo localmente, uma vez que o mercado está cada vez mais segmentado. Neste ponto a autora analisa a crescente influência do comportamento étnico, nas decisões publicitárias e slogans de comunicação da marca fazendo um paralelo com a linguagem e a dificuldade de tradução/compreensão do idioma.

E por fim, o capítulo o Consumidor no Laboratório busca demonstrar a metodologia empregada para pesquisar e compreender o comportamento do consumidor. Essa questão, devido à superficialidade de citação dos conceitos, deixa um pouco a desejar. Algumas técnicas muito utilizadas em pesquisas do consumidor como: autodriving, testes projetivos e grupos de foco ficaram sem revisão, dando uma impressão de precariedade nas técnicas existentes para investigar o comportamento humano, bem ao avesso de Schiffman \& Kanuk (2000) que abordam proveitosamente esses métodos inclusive comparando-os.

Mais do que nunca, compreender o consumidor é uma necessidade vital não apenas para as empresas, mas para toda a organização/instituição que se assuma como orientada para os clientes (Dubois, 1991). Essa obra é direcionada a profissionais de marketing, publicitários e acadêmicos que desejam compreender esta conduta cada vez mais mutante do consumidor. Ao mesmo tempo a leitura é indicada, como livro-texto, a professores dessa área de conhecimento que buscam contribuir ainda mais 
para o crescimento e fortalecimento do campo no Brasil. Mesmo sem possuir um resumo de fixação ou questões ao final dos capítulos a leitura permanece agradável.

Obra de conteúdo abarcante e com uma intrigante conclusão, o livro introduz o leitor na problemática do comportamento de compra do ser humano e propõe um tour através das disciplinas e áreas que consagram o campo. A partir deste importante passo de Eliane, a produção nacional de livros do comportamento do consumidor, principalmente servindo-se de artigos e casos reais em nível nacional poderá receber uma outra prudência e direção, sobretudo, por nós profissionais, pesquisadores e professores da área.

Nota

O autor é extremamente grato ao editor da RAE e ao editor associado, pelos comentários concedidos.

\section{REFERÊNCIAS BIBLIOGRÁFICAS}

DUBOIS, B. Compreender o Consumidor. 2a ed. Lisboa: Publicações Dom Quixote, 1998.

ENGEL, J.F., BLACKWELL, R.D., MINIARD, P.W. Comportamento do Consumidor. $8^{\mathrm{a}}$ ed. Rio de Janeiro: Editora LTC, 2000.

GOLDSTEIN, M., ALMEIDA, H.S. Crítica dos Modelos Integrativos de Comportamento do Consumidor. Revista de Administração-RAUSP, v. 35, n. 1, p. 14-22, Jan./Mar. 2000.

HOLBROOK, M.B. What Is Consumer Research? Journal of Consumer Research, v. 14, p. 128-132, June 1987.

SCHIFFMAN, L.G., KANUK, L.L. Comportamento do Consumidor. $6^{\mathrm{a}}$ ed. Rio de Janeiro: Editora LTC, 2000.

VIEIRA, F.G.D. Ações Empresariais e Prioridades de Pesquisa em Marketing: Tendências no Brasil e no Mundo Segundo a Percepção dos Acadêmicos Brasileiros. In: ENCONTRO NACIONAL DA ASSOCIAÇÃO NACIONAL DOS PROGRAMAS DE PÓS-GRADUAÇÃO EM ADMINISTRAÇÃO, n. 23, 1999, Foz do Iguaçu. Anais... Foz do Iguaçu: Anpad, 1999.

\footnotetext{
${ }^{\mathrm{i}}$ Um dos maiores desbravadores e colaboradores desta área no que tange aos determinantes psicológicos e racionais do comportamento do consumidor foi Ernest Dichter. Handbook of Consumer Motivations. New York: McGraw-Hill, 1964. ii Dentre outros livros nacionais publicados nessa temática destacamos: BENNET, P., KASSARJIAN, H. O Comportamento do Consumidor. São Paulo: Atlas, 1975 e GIGLIO, E. O Comportamento do Consumidor. São Paulo: Pioneira, 1996.
} 